Journal of Advanced Research in Fluid Mechanics and Thermal Sciences

\title{
The Potential of Water-In-Oil Emulsion of Canola Oil as Dielectric Fluid for EDM Process
}

\author{
Norazkifni Faizura Dzulkifli ${ }^{1,}{ }^{*}$, Azuddin Mamat ${ }^{1}$, Imtiaz Ahmed Choudhury ${ }^{1}$ \\ 1 Centre for Production Design \& Manufacturing, Department of Mechanical, Faculty of Engineering, University of Malaya, 50603 Kuala Lumpur, \\ Malaysia
}

\section{ARTICLE INFO}

Article history:

Received 2 March 2020

Received in revised form 30 March 2020

Accepted 31 March 2020

Available online 30 June 2020

\section{Keywords:}

Vegetable oil; dielectric fluid; EDM; W/O

emulsion; thermal properties; viscosity

\section{ABSTRACT}

Currently, the industry generally uses electrical discharge machining (EDM) with kerosene facing problems in terms of processing efficiency, perilous environment, and low quality of the machined surface. In this paper, water-in-oil (W/O) emulsion dielectric is introduced as an alternative for this drawback. Kerosene has low properties especially thermal conductivity, viscosity and, higher heat capacity. Vegetable oil such as canola oil can be selected as an alternative dielectric fluid. This work has measured the properties of canola oil including thermal conductivity, heat capacity and viscosity for possible use as a dielectric fluid. The result shows that the emulsion of canola oil has the best combination at $35 \mathrm{wt} \%$ of Tween 20 with heat applied.

Copyright $@ 2020$ PENERBIT AKADEMIA BARU - All rights reserved

\section{Introduction}

Electrical discharge machining (EDM) is a non-contact machining process for hard-to-cut materials. The evolvement of EDM technology, this method greatly used in the manufacturing industry, electronics industry, fabrication fields including dies, aerospace, tool, surgical field and automotive $[1,2]$. The outstanding performance of EDM can work on simple to complex geometric shapes, nano-scale to macro, extreme to low temperature, even semiconductive and insulating materials [3]. The principle is a metal removal controlled process by transforming electric energy to thermal energy through electrical discharges between the electrode and workpiece with the presence of dielectric fluid [4]. EDM operates with an electric spark act as the cutting tool to wear away the workpiece to turn out into desired shape. Material erosion happens with the presence voltage difference through the electrode to the workpiece, which creates disturbance in dielectric fluid due to strong electrostatic field.

\footnotetext{
* Corresponding author.

E-mail address: norazkifnifaizura@um.edu.my
}

https://doi.org/10.37934/arfmts.72.2.129141 
Fundamental mechanism of EDM technology have been investigate by many researchers with some additional aspects of the process that need for enhancing its performance including choosing suitable material of electrode, medium of dielectric, flushing effect, machining power, polarity of electrode and many more. Hang et al., [5] had investigate the mechanism of sinking electrical discharge machining using water-in-oil nanoemulsion. They investigated single-pulse discharge by using W/O nanoemulsion and kerosene. The results showed when using W/O nanoemulsion critical discharge gap is larger. Generally, nanoemulsion has higher density and viscosity, which leads to stronger restrictions to the plasma channel and the motions of bubbles. This caused larger volumes of melted materials and craters are created. Md Ali et al., [6] studied the performance of different electrode use. They selected copper, copper tungsten, graphite and brass electrode for machining aluminium alloy LM6 (AI-Sil2). It can be concluded that high material removal rate with low surface roughness is created when using electrode graphite. Significantly, copper and copper tungsten generate high surface roughness with low electrode wear rate. Wear of electrode is prevented during machining due to its hardness. Electrode that shows low ability to withstand of spark energy and has the highest EWR is brass. Their study pointed out that melting point and thermal conductivity of electrode materials effect the quality of output machining. Nazriah and Azli studied the effect of power supply on material removal rate. Overall, these results indicate that the Flyback power supply enhanced the steadiness of MRR when compared to Linear power supply. Thus, the production of micro dimples can be improved due to the machining time is able to be predict. Not only that, there also researcher that study genetic algorithm to achieve optimum performances of machining [7].

Dielectric fluid takes an important role in electrical discharge machining operations where it controls the performance of the process. Therefore, to maintain high performance of EDM, there will be additional effort needed to select appropriate dielectric fluid. When running an EDM, there is a procedure call flushing, where it is a process of debris removal from the gap between electrode and workpiece. Besides, dielectric fluid also important to remove gaseous and solid debris from the spark gap area produce during machining and to maintain temperature of dielectric below its flashpoint. Schumacher [8] founds if there are too much debris presence within discharge gap, continuous arc will formed and next will produce unstable machining. As reveal by UhImann et al., [9] dielectric fluid confine tool electrode from workpiece so that current plasma channel creates is at high enough level. This condition is important to reduce the temperature of heated surface, which next will cause plasma channel expansion due to counter pressure built. Therefore, to obtain good surface finish, high accuracy machining and high removal rate with low electrode wear ratio, proper selection of dielectric fluid is compulsory.

Srinivas et al., [10] had summary desired properties of a good dielectric fluid, including low specific gravity, toxicity, viscosity and carbon content. Furthermore, they added, to achieve stable sparking condition dielectric fluid must have high flashpoint, oxygen content, breakdown voltage and high volatility. Biodegradability characteristic will be added value. Makenzi and Ikua [11] stated that to achieve quick recovery after break down, dielectric fluid should have high dielectric strength. Not only that, but they also added high-performance machining can be achieved when dielectric fluid has excellent flushing ability and effective quenching. Dielectric fluid exists in three forms, gaseous, liquid and vacuum. Different dielectric fluids used in EDM are kerosene, water, mineral oil, transformer oil, synthetic oil, dielectric liquid with powder additives, air, oxygen, nitrogen, etc. Among three forms of dielectric fluid, liquid dielectric mostly uses due to their superiority of self-balanced over total or partial condition of total discharges.

Kerosene is probably the most common dielectric fluid for conventional EDM. Kerosene is being selected due to its behaviour that has good flushing quality and low viscosity. In contrast, kerosene has low flash point and very volatile. Due to very volatile, kerosene tends to decompose during 
machining [12]. This cause many hazardous fumes like polycyclic aromatic hydrocarbons (PAHs), vapor of kerosene, aldehydes, acetylene, and ethylene are generate during the machining process [13]. In the manufacturing industry, operators are at high risk when expose to those fumes for a period of time [14]. Moreover, Chen et al., [15] found that, when using kerosene for machining with EDM, dissemination of carbon occur on the machined surface. They added that carbide is deposited on workpiece when kerosene is used as dielectric. Not only that, high temperature localized during machining causes kerosene decomposes to produce carbon, and sticks onto the electrode. In addition, there are researchers that study machining using kerosene with the addition of powder. From their studies reveal that debris produced successfully reduced. The material removal depth and surface roughness also increase. Unfortunately, addition of the powder increase electrode wear rate [16]. The deposited carbon on the electrode tends to reduce the discharge efficiency. In the nutshell, kerosene rises a lot of problems during machining including degradation of its properties and inflammable which can cause fire hazard to the operators. Therefore, further study is needs to search for replacement for kerosene. However, the implementation of changing the dielectrics has to look into the surroundings factors to achieve high MRR, low electrode wear ratio and low surface roughness.

Various attempts study had been done to find new dielectric by researchers to solve issue of unfriendly environment impact and inflammability effect of kerosene in conventional sinking EDM. The replacement to the hydrocarbon oil is firstly suggested water-based. Deionized water, has higher conductivity which will produce lower dielectric strength than hydrocarbon-based dielectric fluids. Due to that, spark trigger more easily at larger gap compared to dielectric oil. Besides that, waterbased dielectric fluid have higher vaporization heat which transfers more thermal energy during machining compared to hydrocarbon-based [9]. Furthermore, deionized water has lower viscosity, higher thermal conductivity and flow rate as compared to hydrocarbon oil. Water-based dielectric gives higher machining rates but cracks formed on the workpiece. Yukinori et al., revealed that formation of the surface cracks are caused by thermal stresses over the machined surface [17]. Deionized water reduces the formation of recast layer because of it has low carbon content. In addition, using deionized water reduces the surface roughness during machining. Yukinori et al., [18] also agrees that MRR and tool wear are improve when using water-based dielectric. Another drawback of water-based dielectric fluid is deionization, high tool wear and erosion of the workpiece.

Furthermore, some researchers use vegetable oil as replacement to kerosene. Valaki et al., [19] use jatropha oil as bio dielectric. They found that there are increasing MRR and surface hardness up to $38 \%$ and $6 \%$ respectively. They add the surface roughness also reduced by $23 \%$. Shirsendu et al., [20] point out the same result in their study by using neem oil, transesterified jatropha and canola oil. Ng et al., [21] had explored the uses of canola biodiesel and sunflower biodiesel as dielectric fluid. They point out that MRR is 114 to $137 \%$ higher when using canola biodiesel and sunflower biodiesel. Not only that, both canola biodiesel and sunflower biodiesel resulted in 27 and $21 \%$ lower TWR when compared to the conventional dielectric. In addition, Valaki et al., [22] also investigate waste vegetable oil-based as dielectric fluid. They found that waste vegetable oil gives higher MRR compares to kerosene. This is due to higher energy density which produce higher breakdown voltage. They added unwanted arc are minimize and produces an excellent sparking cycle.

To make machining cost economically, there are researchers that mixed water into vegetable oil with additional of emulsifier. Hang Dong et al., [23] indicate that there are $44.64 \%$ increase in MRR and $40.33 \%$ decrease in REWR when using W/O nanoemulsion in sinking EDM compared to kerosene. Not only that, they also found that surface of machined workpiece shows fewer cracks with thinner recast. Harmful and toxic gases generate during machining also significantly reduced when using W/O nanoemulsion dielectric [23]. This finding also supports by Zhang et al., [24]. Experimental results 
revealed that W/O emulsion produces larger peak current and longer pulse duration which leads to higher MRR compares to kerosene. In addition, water-in-oil emulsion has lower carbon deposited onto the electrode surface which gives higher REWR. Yonghong et al., [25] had studied w/o emulsion with different types of emulsifiers used. The result highlighted that emulsion-1 and emulsion-2 used in EDM show low SR, high MRR, and high discharge gap, when compared with kerosene. However, in term of electrode wear ratio emulsion-1 show better result that emulsion- 2 when compared to kerosene. In addition, there are researcher that investigate nano-emulsion, Hang et al., [26]. Their study points out that MRR is $34 \%$ higher when compared to kerosene. Furthermore, their finding shows relatively lower REWR are obtained in rough machining, with better machined surface and absence of recast layer. Besides that, W/O nano emulsion also has a higher viscosity, which can be modified by different weight percent of water content. This property produces higher MRR and stable machining. Nevertheless, W/O nano emulsion still much safer and more environmentally friendly owing to the addition of water.

Accordingly, using kerosene has low safety and machining efficiency. Besides, it also gives negative impact to the environment. Previous studies were designed towards stability, improving surface quality, optimization of machining parameter. Unfortunately, very minimum research on sustainability issues. This new alternative dielectric fluid is very useful in expanding our understanding that vegetable oil including jatropha oil, sunflower oil, canola oil, coconut oil, castor oil, olive oil, and even waste vegetable oil can be used in creating green machining for EDM. However, very minimum study had been done and still a lot of missing puzzle in developing sustainable electrical discharge machining. In our case, W/O emulsion was chosen as alternative for dielectric fluid. In this paper, the composition of water content, thermal conductivity, volumetric heat capacity and viscosity were studied by comparing them with kerosene and distilled water. In our work, a systemically experimental analysis of heat property for different dielectrics was performed. The heat property is analyses by using KD2Pro. The viscosity value at room temperature is also investigated by using programmable rheometer.

\section{Methodology}

Water-in-oil emulsion is a mixture of water and canola oil with the presence of emulsifier. While for emulsifier are Tween 20, Tween 60 and Tween 80, which are hydrophilic emulsifying agents. Compositions for W/O emulsions are shown in Table 1.

Table 1

Composition of W/O emulsion

\begin{tabular}{llll}
\hline No & Vegetable Oil & Distilled Water & Emulsifier \\
\hline (a) Comparison by different emulsifier & $90 w t \%$ Canola Oil & $10 w t \%$ & $25 w t \%$ Tween 20 \\
& $90 w t \%$ Canola Oil & $10 w t \%$ & $25 w t \%$ Tween 60 \\
& $90 w t \%$ Canola Oil & $10 w t \%$ & $25 w t \%$ Tween 80 \\
(b) Comparision by different wt\% of Tween 20 & $90 w t \%$ Canola Oil & $10 w t \%$ & $15 w t \%$ Tween 20 \\
with/without applying heat & $90 w t \%$ Canola Oil & $10 w t \%$ & $25 w t \%$ Tween 20 \\
& $90 w t \%$ Canola Oil & $10 w t \%$ & $35 w t \%$ Tween 20 \\
(c) Comparision by different wt\% of Tween 80 & $90 w t \%$ Canola Oil & $10 w t \%$ & $15 w t \%$ Tween 80 \\
with/without applying heat & $90 w t \%$ Canola Oil & $10 w t \%$ & $25 w t \%$ Tween 80 \\
& $90 w t \%$ Canola Oil & $10 w t \%$ & $35 w t \%$ Tween 80 \\
\hline
\end{tabular}

Before the emulsification process, emulsifier is dissolved in the vegetable oil and stirred at $850 \mathrm{rpm}$ for 60 minutes. Then, the emulsified oil is mixed with water at $1000 \mathrm{rpm}$ for 60 minutes. After that, w/o emulsified is poured into a vial for further testing. For part (b) and (c) are further 
stirred at $1000 \mathrm{rpm}$ with the presence of heat for 120 minutes at $75^{\circ} \mathrm{C}$. The experimental set up is shown in Figure 1. The thermal conductivity and volumetric heat capacity are measured using KD2Pro. Viscosity is measured using programmable rheometer and $\mathrm{pH}$ value is measured using $\mathrm{pH}$ meter. Thermal diffusivity is the ratio of the thermal conductivity to the heat capacity.

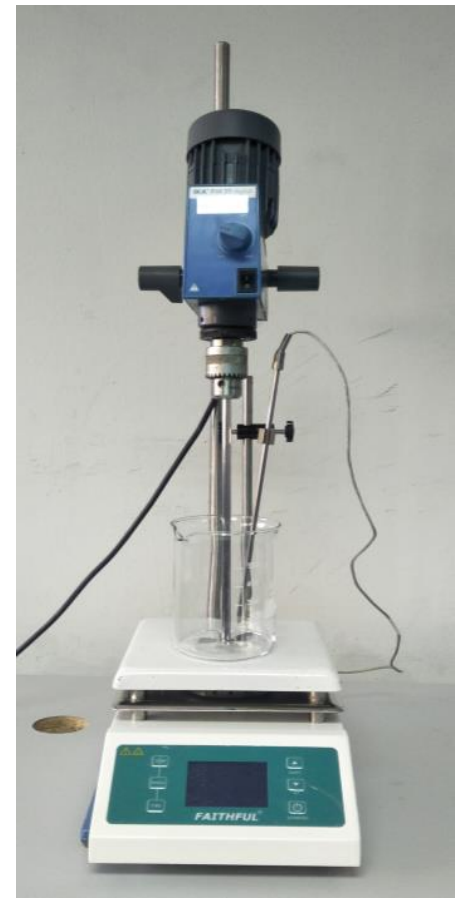

Fig. 1. Experimental set up

\section{Result and Discussion}

Table 2 shows properties of conventional EDM dielectric fluid, distilled water and canola oil. Properties of EDM fluid will be used as control. This study investigates a vegetable oil that has properties nearly the same with conventional EDM dielectric fluid, or even better. A key aspect of high quality EDM dielectric fluid is having high thermal conductivity to assist heat transfer in faster rate. Equally important, EDM dielectric fluid also must have lower value of heat capacity which will reduce the energy need to heat the fluid. Besides, EDM dielectric fluid also must have high viscosity to ease removable of debris during machining. In addition, EDM fluid need high thermal diffusivity value so that material will response faster to thermal change reaching equilibrium state [27].

Table 2

Properties of conventional EDM dielectric fluid, distilled water, and pure canola oil

\begin{tabular}{lllllll}
\hline No & Dielectric fluid & $\begin{array}{l}\text { Thermal conductivity } \\
(\mathrm{W} / \mathrm{m} . \mathrm{K})\end{array}$ & $\begin{array}{l}\text { Volumetric Heat } \\
\text { capacity }\left(\mathrm{MJ} / \mathrm{m}^{3} \cdot \mathrm{K}\right)\end{array}$ & $\begin{array}{l}\text { Thermal } \\
\text { Diffusivity }\left(\mathrm{m}^{2} / \mathrm{M}\right)\end{array}$ & $\mathrm{pH}$ & $\begin{array}{l}\text { Viscosity } \\
(\mathrm{cP})\end{array}$ \\
\hline 1 & Distilled Water & 0.487 & 4.056 & 0.120 & 7.21 & 1.06 \\
2 & EDM Fluid & 0.114 & 0.777 & 0.147 & 5.05 & 3.28 \\
3 & Canola (pure) & 0.142 & 1.208 & 0.118 & 4.46 & 54.2 \\
\hline
\end{tabular}

From Table 2, distilled water has the highest value of thermal conductivity. In contrast, canola oil has thermal conductivity and heat capacity moderate low and nearly to conventional EDM dielectric fluid value. Another factor that emerged from the data was viscosity value which important in 
removing debris. Canola oil has the highest number of viscosity value conversely distilled water has the smallest viscosity.

Tables 3, 4 and 5 indicate the variation of thermal conductivity, heat capacity and viscosity with different concentration and type of emulsifier respectively. The result for thermal conductivity, heat capacity and viscosity for different Tween 20 weight percent have been depicted in Figure 2 . From Figure 2, it is apparent that $15 \mathrm{wt} \%$ of Tween 20 without heating has the highest value for thermal conductivity. Also, $15 \mathrm{wt} \%$ of Tween 20 with the presence of heat has the lowest value of volumetric heat capacity. While, emulsion that show the highest viscosity is $35 w t \%$ Tween 20 without heating. As well, 35\% of Tween20 with heating shows the highest value of thermal diffusivity. Perhaps the most significant finding is $35 \mathrm{wt} \%$ Tween 20 with heat applied show the best fit for good EDM dielectric fluid replacement. This emulsion has moderate value for thermal conductivity, heat capacity and viscosity. This characteristic will improve the performance of dielectric fluid during actual EDM machining.

\section{Table 3}

Properties of dielectric fluid based on different weight percent of tween 20 used

\begin{tabular}{lllllll}
\hline \multirow{2}{*}{ Dielectric fluid } & $\begin{array}{l}\text { Heat } \\
\text { applied }\end{array}$ & $\begin{array}{l}\text { Thermal conductivity } \\
(\mathrm{W} / \mathrm{m} . \mathrm{K})\end{array}$ & $\begin{array}{l}\text { Volumetric Heat } \\
\text { Capacity }\left(\mathrm{MJ} / \mathrm{m}^{3} . \mathrm{K}\right)\end{array}$ & $\begin{array}{l}\text { Thermal } \\
\text { Diffusivity }\left(\mathrm{m}^{2} / \mathrm{M}\right)\end{array}$ & $\begin{array}{l}\mathrm{pH} \\
\text { Viscosity } \\
(\mathrm{cP})\end{array}$ \\
\hline 15wt\% Tween20 & No & 0.182 & 0.590 & 0.308 & 8.140 & 136.800 \\
$25 \mathrm{wt} \%$ Tween20 & No & 0.149 & 0.444 & 0.336 & 8.260 & 100.800 \\
$35 \mathrm{wt} \%$ Tween20 & No & 0.118 & 0.897 & 0.132 & 8.550 & 220.200 \\
$15 \mathrm{wt} \%$ Tween20 & Yes & 0.125 & 0.358 & 0.349 & 7.260 & 58.400 \\
25wt\% Tween20 & Yes & 0.149 & 0.453 & 0.329 & 8.130 & 89.400 \\
$35 \mathrm{wt} \%$ Tween20 & Yes & 0.143 & 0.376 & 0.380 & 8.490 & 133.200 \\
\hline
\end{tabular}

\section{Table 4}

Properties of dielectric fluid based on different weight percent of tween 80 used with presence of heat

\begin{tabular}{lllllll}
\hline \multirow{2}{*}{ Dielectric fluid } & $\begin{array}{l}\text { Heat } \\
\text { applied }\end{array}$ & $\begin{array}{l}\text { Thermal conductivity } \\
(\mathrm{W} / \mathrm{m} . \mathrm{K})\end{array}$ & $\begin{array}{l}\text { Volumetric Heat } \\
\text { Capacity }\left(\mathrm{MJ} / \mathrm{m}^{3} . \mathrm{K}\right)\end{array}$ & $\begin{array}{l}\text { Thermal Diffusivity } \\
\left(\mathrm{m}^{2} / \mathrm{M}\right)\end{array}$ & $\begin{array}{l}\text { Viscosity } \\
\text { (cP) }\end{array}$ \\
\hline 15wt\% Tween80 & No & 0.161 & 0.620 & 0.260 & 6.050 & $>>500$ \\
25wt\% Tween80 & No & 0.173 & 0.735 & 0.235 & 6.390 & 126.600 \\
35wt\% Tween80 & No & 0.181 & 0.968 & 0.187 & 6.640 & 199.800 \\
$15 w t \%$ Tween80 & Yes & 0.038 & 0.753 & 0.050 & 5.740 & 75.000 \\
25wt\% Tween80 & Yes & 0.084 & 0.551 & 0.152 & 6.090 \\
35wt\% Tween80 & Yes & 0.131 & 0.431 & 0.304 & 6.350 & 154.200 \\
\hline
\end{tabular}

Table 5

Properties of dielectric fluid based on different emulsifier used

\begin{tabular}{lllll}
\hline Emulsifier & $\begin{array}{l}\text { Thermal conductivity } \\
(\mathrm{W} / \mathrm{m} . \mathrm{K})\end{array}$ & $\begin{array}{l}\text { Volumetric Heat Capacity } \\
\left(\mathrm{MJ} / \mathrm{m}^{3} . \mathrm{K}\right)\end{array}$ & $\begin{array}{l}\text { Thermal Diffusivity } \\
\left(\mathrm{m}^{2} / \mathrm{M}\right)\end{array}$ & $\begin{array}{l}\text { Viscosity } \\
(\mathrm{cP})\end{array}$ \\
\hline Tween20 & 0.149 & 0.444 & 0.336 & 100.800 \\
Tween60 & 0.125 & 0.581 & 0.215 & 138.000 \\
Tween80 & 0.173 & 0.735 & 0.235 & 126.600 \\
\hline
\end{tabular}




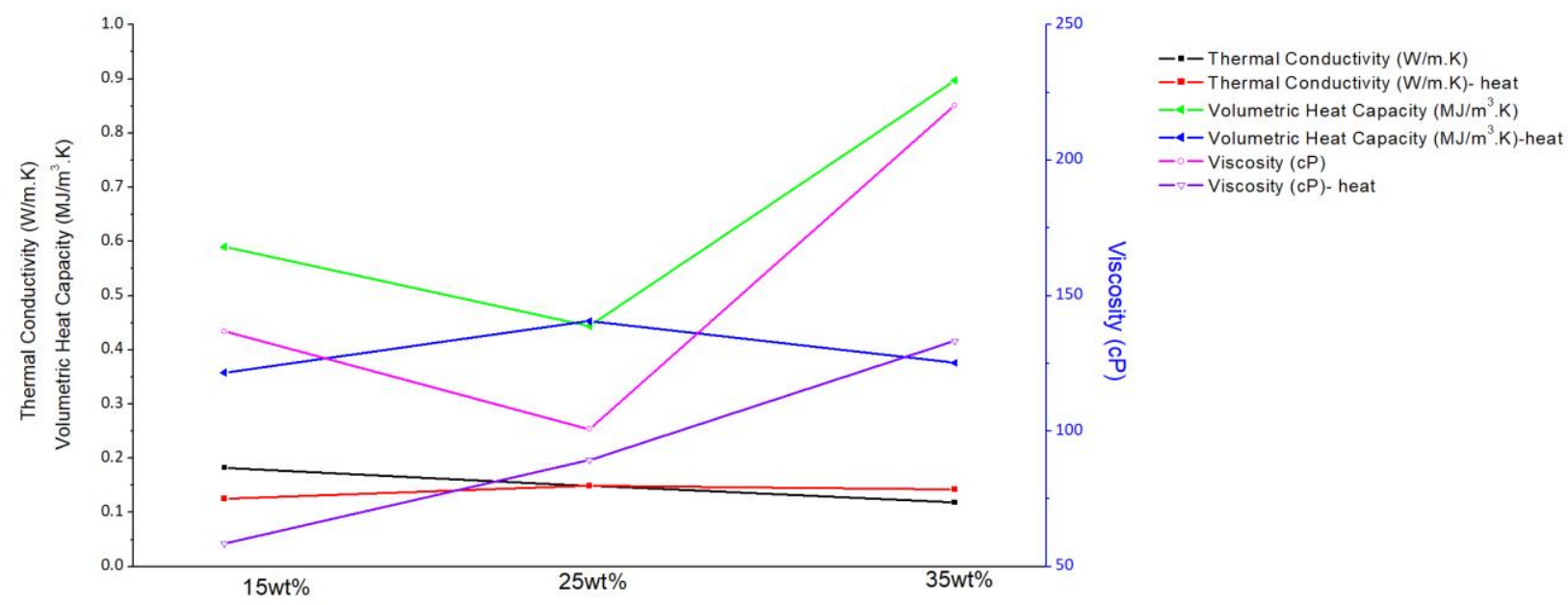

Fig. 2. Comparison of thermal conductivity, heat capacity and viscosity when different weight percent of Tween20 applied

Figure 3 shows $35 w t \%$ Tween 80 without heating has the highest value for thermal conductivity. In contrast, $35 \mathrm{wt} \%$ Tween 80 with heat applied has the lowest value for volumetric heat capacity and the highest thermal diffusivity. While, for viscosity value, $15 \mathrm{wt} \%$ Tween 80 without heating shows the highest.

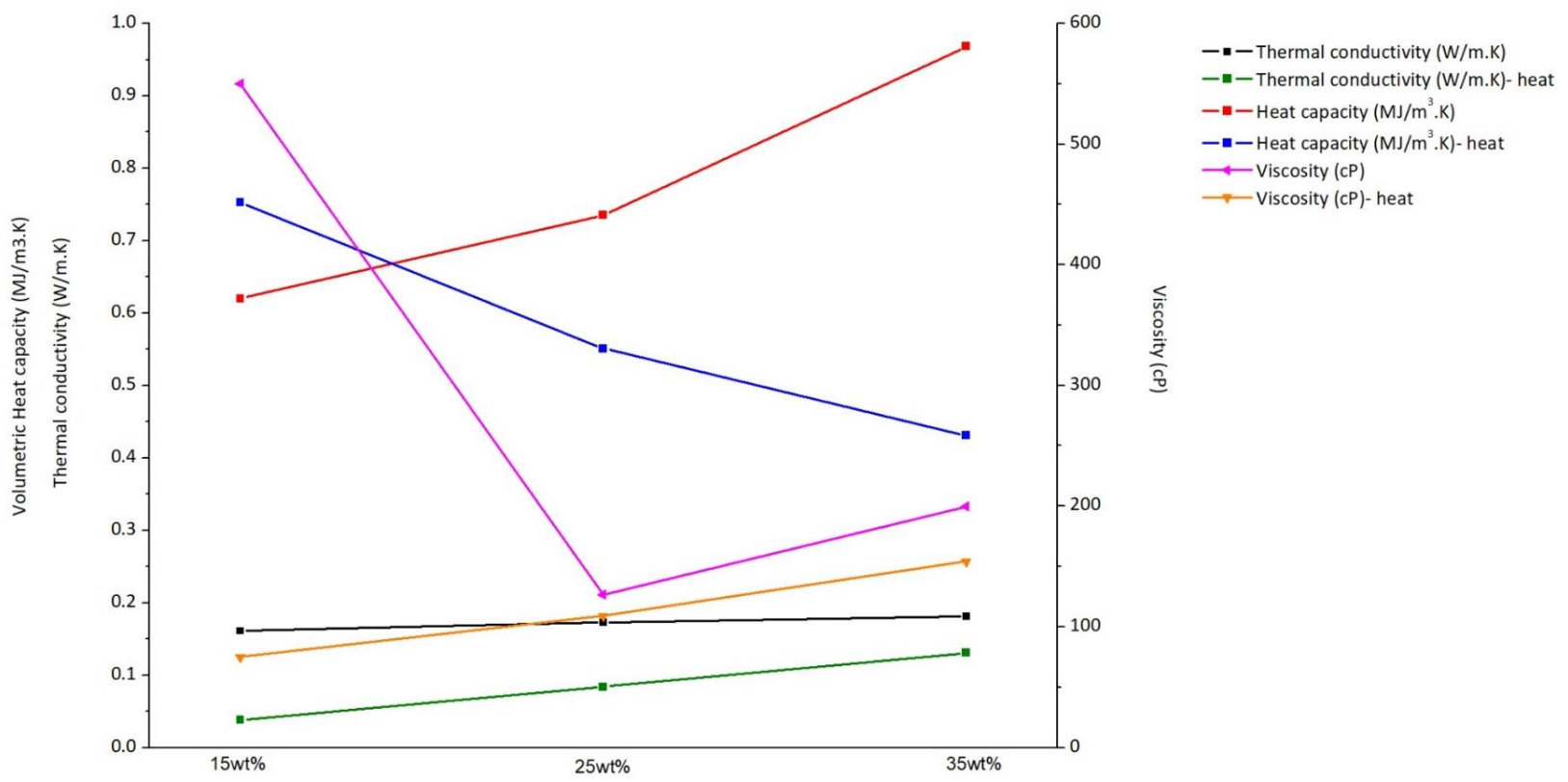

Fig. 3. Comparison of thermal conductivity, heat capacity and viscosity when different weight percent of Tween80 applied

Figure 4 and Table 5 show by using different emulsifier will give effect on the value of thermal conductivity, heat capacity and viscosity. Surprisingly, Tween20 is found can reduce heat capacity while Tween 80 can increase thermal conductivity value. As well as Tween60 able to improve viscosity value. Looking at Figure 4 and Table 5 , it is apparent that using $25 \mathrm{wt} \%$ Tween 80 has the highest value for thermal conductivity. In addition, by using $25 \mathrm{wt} \%$ Tween 20 gives the best dielectric fluid in term of heat capacity. While by adding $25 \mathrm{wt} \%$ of Tween 60 increases the viscosity of the dielectric fluid. Among these three emulsifier Tween 20 gives the highest thermal diffusivity. 
In general, thermal conductivity decreases with increasing of temperature due to density gradient created. Then, buoyancy force will be generated that will against the viscous resistance of the fluid. Which next imbalance thermal will results decreasing in thermal conductivity [28-29]. Thermal conductivity mostly relies on molecular diffusion effect. In addition, randomness of molecular movement increases aligns with increasing of temperature. This occlude transportation of heat across the liquid which causes the thermal conductivity of liquid decreases when temperature increase. Previous study by Hoffman [30] had successfully demonstrate this pattern, where for all investigated vegetable oils, the thermal conductivity decreases when the temperature increases. However, the findings of the current study do not support the previous research. This inconsistency may be due to this study focus on emulsification, where the system is a mixture of distilled water, emulsifier and vegetable oil, dispute previous study using pure oil.

Specific heat increases with the increasing in temperature due to expansion of a substance during heating. Some of the heat absorb are for the expansion of that material against the surroundings [31]. This study had been unable to demonstrate this early finding. This may due to previous research using pure vegetable oil. The result of this experiment shows no clear pattern for thermal behaviour, either thermal conductivity or heat capacity value.

Rojas et al., [32] point out that viscosity of the oils decrease approximately in $3 \%$ for each additional of $1^{\circ} \mathrm{C}$. This finding also was early reported by Ullmann [33] where viscosity of oil decreases by approximately $30 \%$ for each $10^{\circ} \mathrm{C}$ rise in temperature. Significantly, the liquid deflates when temperature increase. This is due to microscopic level with increasing temperature will increase the mobility of molecules. Next, will causes decreasing of the efficiency phonon heat transport [30]. Consistent with the literature, this research found that when emulsion being heat, their viscosities will decrease.

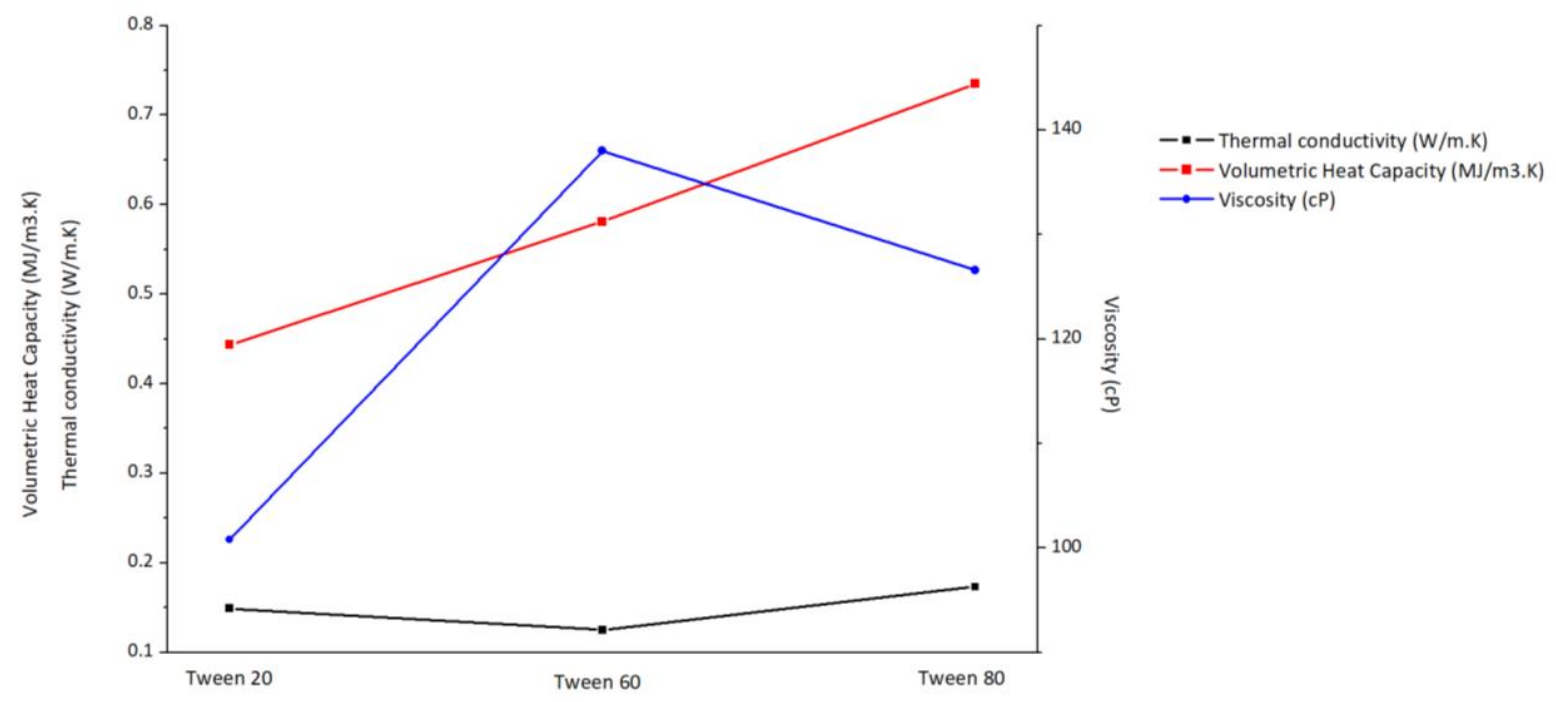

Fig. 4. Properties of dielectric fluid based on different emulsifier used

From Tables 6 and 7, by increasing weight percent of emulsifier, it will improve emulsion stability for 24 hours. Only $15 \mathrm{wt} \%$ of emulsifier fails the stability test for both Tween 20 and Tween 80 . Besides that, temperature also has effect on stability. For both case Tween 20 and Tween 80 at $15 w t \%$ of emulsifier, stability improve when the emulsion is heated. These results are concurrent with previous study done by Komaiko and McClements [34]. They found that temperature do affect the stability of the emulsions, independent of the preparation method. 


\section{Table 6}

Stability test of dielectric fluid based on different weight percent of tween 20 used with/without presence of heat

Dielectric fluid


Table 7

Stability test of dielectric fluid based on different weight percent of tween 80 used with/without presence of heat

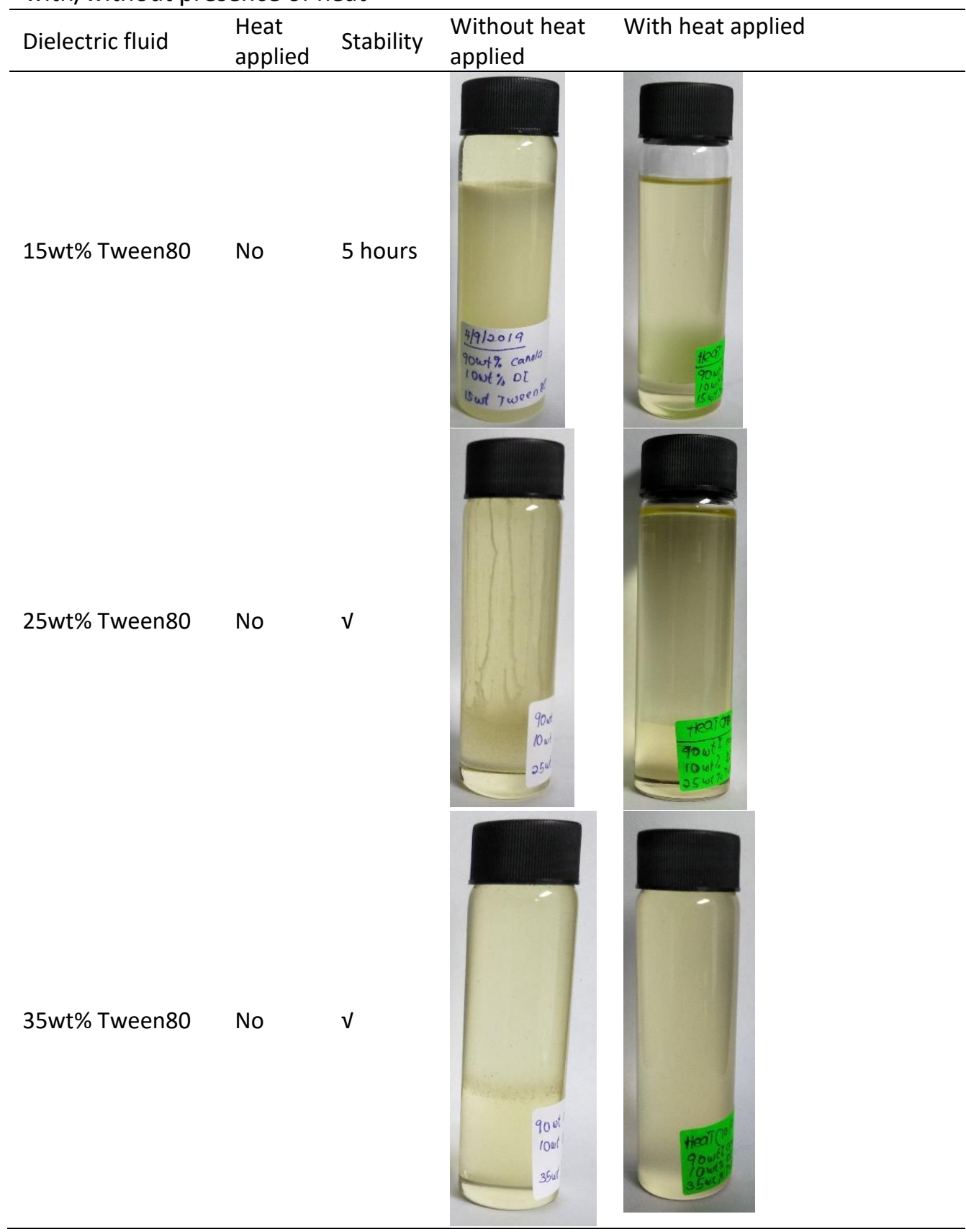

\section{Conclusions}

The selection of dielectric fluid for EDM is an important task as it reflects the performance, economic and environmental impact of process. It does not only function to remove melted metal from discharge gap but also influence the performance of machining. Up to now, a number of studies were done to improve EDM performance in terms of MRR, surface finish, electrode wear, using different dielectric fluids like water-based, powder mixed dielectric, water with additives, gas dielectric, etc. This work has measured the properties of canola oil including thermal conductivity, heat capacity and viscosity aiming to have a view on the potential of dielectrics fluid. A high-quality dielectric fluid must have high thermal conductivity to assist heat transfer in faster rate. Our study 
successfully produce emulsion that has higher thermal conductivity that kerosene when using Tween 20 for $15 \%$ to $35 \mathrm{wt} \%$ water content, in contrast the trend not apply when using Tween 80 . Whereas for volumetric specific heat capacity must have lower value. This is important to reduce the energy needs to heat the fluid. Our finding successfully reduces volumetric heat capacity for both when using Tween 20 and Tween80 for all water content percentage. While for viscosity value must have higher value so that the debris forms are easily removed from discharge gap. For both, using Tween 20 and Tween 80 as emulsifier show higher value of viscosity when compared to kerosene. Unfortunately, this paper has argued that with heat applied, thermal conductivity will decrease and heat capacity will increase. In contrast, viscosity behaviour does support previous study, where the viscosity value decrease when heat applied. The current study shows all the viscosity value reduced after being heated. Among all experiment had been done, canola oil with $35 \mathrm{wt} \%$ of Tween 20 with heat applied shows the best properties to be selected as replacement for conventional EDM fluid. Even do this study not supporting previous research, this study somewhat useful finding as previous study less focus on water in oil emulsion behaviour as alternative EDM fluid. The present study will serve as a base for future studies in exploring water-in-oil emulsion as replacement for kerosene as conventional EDM fluid. This is due to W/O emulsion is more safe, efficient, cheaper, and able to create green manufacturing of sinking EDM next in the future.

\section{Acknowledgement}

This research was funded by a grant from Ministry of Higher Education of Malaysia (FRGS Grant FP098-2018A \& GPF037A-2018).

\section{References}

[1] Qinhe Zhang Kan Wang, and Jianhua Zhang. "Evaluation of scale effect of micro electrical discharge machining system." Journal of Manufacturing Processes 38, (2019): 174-178.

https://doi.org/10.1016/i.jmapro.2019.01.005

[2] Hamidullah Yasar Tahsin T. Öpöz, Nihal Ekmekci, and Bülent Ekmekci. "Particle migration and surface modification on Ti6Al4V in SiC powdermixed electrical discharge machining." Journal of Manufacturing Processes 31, (2018): 744-758. https://doi.org/10.1016/i.jmapro.2018.01.002

[3] Kunieda, M., Bert Lauwers, Kamlakar P. Rajurkar, and B. M. Schumacher. "Advancing EDM through fundamental insight into the process." CIRP annals 54, no. 2 (2005): 64-87.

https://doi.org/10.1016/S0007-8506(07)60020-1

[4] Jaber E. Abu Qudeiri, Abdel-Hamed I. Mourad, Aiman Ziout, Mustufa Haider Abidi, and Ahmed Elkaseer. "Electric discharge machining of titanium and its alloys: review." The International Journal of Advanced Manufacturing Technology 96, no. 1-4 (2018): 1319-1339. https://doi.org/10.1007/s00170-018-1574-0

[5] Dong, Hang, Ming Li, Tong Liu, Yu Zhou, Yang Shen, Chi Ma, Xianwei Zhang, and Yonghong Liu. "Mechanism study of sinking electrical discharge machining using water-in-oil nanoemulsion." The International Journal of Advanced Manufacturing Technology 105, no. 5-6 (2019): 2309-2320. https://doi.org/10.1007/s00170-019-04468-6

[6] Ali, M. M., S. Laily, B. Manshoor, N. Syahrian, R. Izamshah, M. Hadzley, and M. Muhamad. "Performance of copper, copper tungsten, graphite and brass electrode on MRR, EWR and SR of aluminium LM6 in EDM die sinking." Journal of Advanced Research in Applied Mechanics 6, no. 1 (2015): 30-36.

[7] Yusoff, Y., A. M. Zain, and H. Haron. "Experimental study of genetic algorithm optimization on WC/Co material machining." Journal of Advanced Research in Materials Science 21, no.1 (2016): 14-26.

[8] Schumacher, Bernd M. "About the role of debris in the gap during electrical discharge machining." CIRP annals 39, no. 1 (1990): 197-199. https://doi.org/10.1016/S0007-8506(07)61034-8

[9] Eckart Uhlmann, Markus Röhner, and Malte Langmack. Chapter 3 - Micro-EDM in micro and nano technologies. MicroManufacturing Engineering and Technology, William Andrew Publishing, Boston, Page 39-58, 2010. https://doi.org/10.1016/B978-0-8155-1545-6.00003-X 
[10] Viswanth, V. Srinivas, R. Ramanujam, and G. Rajyalakshmi. "A review of research scope on sustainable and ecofriendly electrical discharge machining (E-EDM)." Materials Today: Proceedings 5, no. 5 (2018): 12525-12533. https://doi.org/10.1016/i.matpr.2018.02.234

[11] Makenzi, M. M., and B. W. Ikua. "A review of flushing techniques used in electrical discharge machining." In Proceedings of Sustainable Research and Innovation Conference, pp. 162-165. 2014.

[12] Kou, Zhaojun, and Fuzhu Han. "On sustainable manufacturing titanium alloy by high-speed EDM milling with moving electric arcs while using water-based dielectric." Journal of Cleaner Production 189 (2018): 78-87. https://doi.org/10.1016/i.jclepro.2018.04.072

[13] Leão, Fábio N., and lan R. Pashby. "A review on the use of environmentally-friendly dielectric fluids in electrical discharge machining." Journal of materials processing technology 149, no. 1-3 (2004): 341-346.

[14] Ross, Andrew S., Kay Teschke, Michael Brauer, and Susan M. Kennedy. "Determinants of exposure to metalworking fluid aerosol in small machine shops." Annals of occupational hygiene 48, no. 5 (2004): 383-391.

[15] Chen, S. L., B. H. Yan, and F. Y. Huang. "Influence of kerosene and distilled water as dielectrics on the electric discharge machining characteristics of Ti-6A1-4V." Journal of Materials Processing Technology 87, no. 1-3 (1999): 107-111. https://doi.org/10.1016/S0924-0136(98)00340-9

[16] Chow, Han-Ming, Biing-Hwa Yan, Fuang-Yuan Huang, and Jung-Cherng Hung. "Study of added powder in kerosene for the micro-slit machining of titanium alloy using electro-discharge machining." Journal of Materials Processing Technology 101, no. 1-3 (2000): 95-103. https://doi.org/10.1016/S0924-0136(99)00458-6

[17] Kunleda, Masanori, Yukinori Miyoshi, Tsutomu Takaya, Nobuhiro Nakajima, Yu ZhanBo, and Masahiro Yoshida. "High speed 3D milling by dry EDM." CIRP Annals 52, no. 1 (2003): 147-150. https://doi.org/10.1016/S0007-8506(07)60552-6

[18] Newman, Stephen T., A. Nassehi, R. Imani-Asrai, and V. Dhokia. "Energy efficient process planning for CNC machining." CIRP Journal of Manufacturing Science and Technology 5, no. 2 (2012): 127-136. https://doi.org/10.1016/i.cirpj.2012.03.007

[19] Valaki, Janak B., Pravin P. Rathod, and C. D. Sankhavara. "Investigations on technical feasibility of Jatropha curcas oil based bio dielectric fluid for sustainable electric discharge machining (EDM)." Journal of Manufacturing Processes 22 (2016): 151-160. https://doi.org/10.1016/j.jmapro.2016.03.004

[20] Das, Shirsendu, Swarup Paul, and Biswanath Doloi. "An experimental and computational study on the feasibility of bio-dielectrics for sustainable electrical discharge machining." Journal of Manufacturing Processes 41 (2019): $284-$ 296. https://doi.org/10.1016/j.jmapro.2019.04.005

[21] Ng, Pei Shan, S. A. Kong, and S. H. Yeo. "Investigation of biodiesel dielectric in sustainable electrical discharge machining." The International Journal of Advanced Manufacturing Technology 90, no. 9-12 (2017): 2549-2556. https://doi.org/10.1007/s00170-016-9572-6

[22] Valaki, Janak B., and Pravin P. Rathod. "Assessment of operational feasibility of waste vegetable oil based biodielectric fluid for sustainable electric discharge machining (EDM)." The International Journal of Advanced Manufacturing Technology 87, no. 5-8 (2016): 1509-1518. https://doi.org/10.1007/s00170-015-7169-0

[23] Yonghong Liu Hang Dong, Ming Li, Yu Zhou, Tong Liu, Dege Li, Qiang Sun, Yanzhen Zhang, and Renjie Ji. "Sustainable electrical discharge machining using water in oil nanoemulsion". Journal of Manufacturing Processes 46 (2019): 118-128.

https://doi.org/10.1016/i.jmapro.2019.08.035

[24] Yanzhen Zhang, Yonghong Liu, Renjie Ji, Baoping Cai, and Yang Shen. "Sinking EDM in water-in-oil emulsion". The International Journal of Advanced Manufacturing Technology 65, no. 5-8 (2012): 705-716. https://doi.org/10.1007/s00170-012-4210-4

[25] Yonghong Liu, Yanzhen Zhang, Renjie Ji, Baoping Cai, Fei Wang, Xiaojie Tian, and Xin Dong. "Experimental Characterization of Sinking Electrical Discharge Machining Using Water in Oil Emulsion as Dielectric". Materials and Manufacturing Processes 28, no. 4 (2013): 355-363.

https://doi.org/10.1080/10426914.2012.700162

[26] Hang Dong, Yonghong Liu, Tong Liu, Ming Li, Yu Zhou, Dege Li, and Qiang Sun. "Water-in-oil nanoemulsion dielectric for both rough and finishing electrical discharge machining". The International Journal of Advanced Manufacturing Technology 104, no. 1-4 (2019): 1485-1495. https://doi.org/10.1007/s00170-019-04028-y 
[27] Bergman, Theodore L., Frank P. Incropera, David P. DeWitt, and Adrienne S. Lavine. Fundamentals of heat and mass transfer. John Wiley \& Sons, 2011.

[28] Turgut, Alpaslan, Ismail Tavman, and Sebnem Tavman. "Measurement of thermal conductivity of edible oils using transient hot wire method." International Journal of Food Properties 12, no. 4 (2009): 741-747. https://doi.org/10.1080/10942910802023242

[29] Codreanu, C., N. I. Codreanu, and V. V. N. Obreja. "Experimental set-up for the measurement of the thermal conductivity of liquids." Romanian Journal of Information Science and Technology 10, no. 3 (2007): 215-231.

[30] Hoffmann, J-F., J-F. Henry, G. Vaitilingom, Régis Olivès, M. Chirtoc, D. Caron, and X. Py. "Temperature dependence of thermal conductivity of vegetable oils for use in concentrated solar power plants, measured by 3omega hot wire method." International Journal of Thermal Sciences 107 (2016): 105-110.

https://doi.org/10.1016/i.ijthermalsci.2016.04.002

[31] Manavendra.G Vinay Atgur, and G.P.Desai. "Experimental Investigation of Thermal Conductivity and Specific Heat and Thermal Degradation of Vegetable Oils For A Range Of Temperature". Research Journal of Chemical and Environmental Sciences 4, no. 4S (2016): 107-111.

[32] Edwin E. Garcia Rojas, Jane S. R. Coimbra, and Javier Telis-Romero. "Thermophysical Properties of Cotton, Canola, Sunflower and Soybean Oils as a Function of Temperature". International Journal of Food Properties 16, no. 7 (2013): 1620-1629. https://doi.org/10.1080/10942912.2011.604889

[33] Timms, R. E. "Physical properties of oils and mixtures of oils." Journal of the American Oil Chemists' Society 62, no. 2 (1985): 241-249. https://doi.org/10.1007/BF02541385

[34] Komaiko, Jennifer, and David Julian McClements. "Optimization of isothermal low-energy nanoemulsion formation: Hydrocarbon oil, non-ionic surfactant, and water systems." Journal of colloid and interface science 425 (2014): 59 66.

https://doi.org/10.1016/i.jcis.2014.03.035 